\title{
A Profile of Male Adolescents Background and Experiences in Substance Abuse
}

\author{
I. Fauziah ${ }^{1}$, S. Nen ${ }^{1}$, M. A. Nur Saadah ${ }^{1} \&$ N. Sarnon ${ }^{1}$ \\ ${ }^{1}$ School of Psychology and Human Development, Faculty of Social Sciences and Humanities, Universiti \\ Kebangsaan Malaysia, Bangi, Malaysia \\ Correspondence: I. Fauziah, School of Psychology and Human Development, Faculty of Social Sciences and \\ Humanities, Universiti Kebangsaan Malaysia, 43600 UKM, Bangi, Selangor, Malaysia. Tel: 60-19-307-1110. \\ E-mail: ifauziah@ukm.my
}

Received: May 29, 2012 Accepted: June 16, 2012 Online Published: September 20, 2012

doi:10.5539/ass.v8n12p109 URL: http://dx.doi.org/10.5539/ass.v8n12p109

\begin{abstract}
Understanding profiles and experiences of adolescents who start using drugs is crucial in developing effective substance abuse interventions and treatment. Thus, this study was to identify the profiles and experiences of adolescents involvement in substance abuse. In total, 200 adolescents from three juvenile Henry Gurney school in Malaysia took part in this exploratory cross section research design. All of these respondents were positively identified involved with drugs. A set of questionnaires were administered to the respondents in group. Results of the study showed that majority of respondents (49 percent) reported to start using drugs at age of 14-16. Most of respondents ( 58.5 percent) had been arrested for the first time to undergo a rehabilitation process under the supervision of the Prison Department of Malaysia. In term of drug using pattern, 45.6 percent reported to consistently using drug ever day while almost half (49.5 percent) obtained their drugs from illegal drugs suppliers. The study also identified that cocaine (65 percent) and marijuana drug ( 54.5 percent) are the most popular drugs used by an adolescents. Findings suggest that rehabilitation and drug prevention programs should take into account regarding the client's background and their drug experience to ensure that drug rehabilitation process can be implemented more effectively to the client of various ages.
\end{abstract}

Keywords: profile, drug experiences, male adolescents, substance abuse

\section{Introduction}

Drug abuse is a major public health problem all over the world (UNODC, 2005). Due to its negative effects on health, economic and social wellbeing, Malaysia government has declared the drug abuse to be the nation 'number one' enemy in 1983. This declaration was followed by stringent law enforcement together with rehabilitation programs for addict (Fauziah \& Naresh, 2009). Malaysia was not a drugs producing countries, but the use and abuse of drugs by adolescents have become one of the most disturbing health related phenomena. To date, symptoms related to drug abuse not only affect adults but also adolescents. Therefore, information about adolescents drug use is crucial for government and related organizations in developing effective drug education and prevention programs.

According to Okoye (2001) a drug refers to a substance that could bring about a change in the biological function through its chemical actions. It is also considered as a substance that modifies perceptions, cognition, mood, behavior and general body functions (Balogun, 2006). They could thus, be considered as chemical modifiers of the living tissues that could bring about physiological and behavioral changes (Nnachi, 2007). Substance use among adolescents is particularly dangerous because it is associated with several behaviors and conditions that are seen as disruptive to the normal functioning of individuals and society at large. These include, school-related problems (Crowe,1998), sexual risk behaviors (Lejuez, Bornovalova, Daughters, et al., 2005; Kokotailo, 1995), juvenile crime and developmental problems (Synder, H.N., Sickmund, 1999), increases in disease such as HIV and Hepatitis (Wells, Fisher, Fenaughty, et al., 2006) and also can increases in frequency of partner violence's (Stuart, Temple, Follansbee, et al., 2008).

Statistics reported by the National Anti-Drugs Agency of Malaysia (2010), indicated that the number of drug addicts among adolescents between age of 13-24 years has increased. Comparison of two-year data released for the year 2009 and 2010 found that the rates of adolescent drug addicts has increased dramatically. A total number 
of 8,163 young adolescent drug addicts were detected during the year 2010 compared to 3,352 people involved in drugs recorded in 2009 (Drug Agency Report, 2010). These statistics provide strong evidence that these problems should be addressed immediately to form a Malaysia drug-free society by the year 2015 (Fauziah, et.al, 2010; Fauziah, et al., 2012). Therefore, an immediate action to further improve the prevention and drug rehabilitation program must be implemented through this research to help the nation to counter the drug problem effectively by taking into consideration the profile and experience of drug addiction among adolescent. Numerous studies found that some adolescents have been identified using prescription drugs to get high and often turn to prescription medications to relieve anxiety, to help sleep better, to enhance concentration, to lose weight, and to relieve pain (Boyd, McCabe, Cranford, \& Young, 2006; Friedman, 2006). However, taking drugs at an early age could affect the health and well-being of adolescents. Research conducted by Dennis (2002) found that more than 90 percent of adults with current substance use disorders started using drugs before age 18 and half of those began before age 15 . The involvement of adolescents in early stage of age in drugs will be able to affect the healthy and intellectual growth of adolescents if not effectively addressed. According to Foster (2012) adolescents who start abusing alcohol or drugs at an early stages of age are at much greater risk of developing an addiction later in life compared to those who misuse drugs later.

Based on the type of drugs, Malaysia drug report revealed that heroin had the highest users in 2011 compared to other type of drugs with a total number of 4,452 followed by morphine (3, 465 users), and methamphetamine (1, 588 users) (Drug Report, 2012). All these drugs can bring negative effect to the developmental of emotional, physical and mental health of drug users. Many researchers have linked a range of drugs, particularly cocaine and amphetamines (including methamphetamine) with increased violence and aggressive behavior (Boles and Miotto, 2003; Davis, 1996; Moore \& Stuart, 2003; Chermack \& Blow, 2002; MacDonald, et al., 2008). Further, a study conducted by Friedman (2006) stated that the long-term effects of drug use may cause on the developing an adolescent brain. The changes also may involve mood swings, alteration in memory processes, or impairment of motor skills (Leshner, 2005). Research has demonstrated that the brain is still developing during adolescence and drug misuse during this developmental period could result in permanent cognitive damage (Giedd, 2008; Gogtay, Giedd, Lusk, Hayashi, Greenstein, Vaituzis, Nugent, Herman, Clasen, Toga, Rapoport, \& Thompson, 2004). However, most of these studies did not specifically examine the profile and experience by different age of groups, especially among young adolescent.

There is ample evidence to show that drugs can have detrimental effects on adolescents. Therefore, an effective planning module that can provide comprehensive interventions and treatment to drug users, especially among adolescents need to be mobilized by taking into consideration their profile and experience in relation to drug use. Treatment for adolescents also must be addressed according to their unique developmental needs, which tend to vary. For example according to Center for Substance Abuse Treatment (1999), developmental features of younger adolescents are different from those of older adolescents. Based on the scenario of current drug abuse among adolescents and a lack of research focusing on the experience and profile of drugs among male adolescents aged between 13-24 years, then a such study related to an experience of adolescent substance abuse should be conducted promptly. Thus, this study was conducted therefore to identify the profile and experiences of male adolescents' involvement in substance abuse. Research findings is expected to contribute to a comprehensive drug prevention program for adolescents and also to move toward Malaysian goal to be a drug free country by 2015. The results of the study also expected to provide a new empirical data as a reference to the counselor, psychologists and social workers associated with the profile and experience of substance abuse trends among adolescent.

\section{Materials and Methods}

This research used cross-sectional survey and the data were analyzed by using descriptive analysis. The questionnaire used in the study was developed by the researchers and consisted of three parts. In the first portion of the questionnaire, respondents provided demographic information including ethnicity, religion, marital status, education, and employment. The questions in this part only allow one answer to be chosen. In the second section, respondents were asked about their drug abuse behaviors such as age of onset of drug use and duration of drug abuse. Also, respondents were asked about the frequency of entering drug rehabilitation center. This part allow the respondents considerable freedom in answering. The final section consisted of multiple choices items that allow respondents to choose more than one answer. Respondents were asked about type of drugs they consumed and source of suppliers.Prior to the research, the researchers sought permission from Director General of the Department of Malaysian Prison to conduct a study at three Henry Gurney Schools. The purpose of the study and confidentiality issue were clearly explained. The research instruments were only distributed after written consents were obtained from the Department of Malaysian Prison. A total number of 200 respondents were 
chosen using stratified random sampling as shown in Table 1. (see Table 1). The questionnaires were then distributed to the adolescents aged between 13 to 21 years and were later collected by counselors from the respective Henry Gurney school. This procedure has achieved a high response rate $(100 \%)$ for this study. This is due to the high degree of cooperation between the respondents and the centers' counselors. The data were then analyzed using descriptive statistics.

Table 1. Number of respondents by states

\begin{tabular}{llc}
\hline Institution & State & $(\mathbf{n = 2 0 0 )}$ \\
\hline Integriti School, Kajang & Selangor & 60 \\
Henry Gurney School, Keningau & Sabah & 50 \\
Henry Gurney School, Telok Mas & Melaka & 90 \\
\hline
\end{tabular}

\section{Results and Discussion}

Age: The minimum age of male adolescents involved in substance abuse was 15 while maximum age was 21 . Specifically, 59.5 percent (120 respondents) of the total respondent age between 19-21 years old and 40.5 percent (81 respondents) age between 15-18 years old. Based on age information, all of the respondents were considered adolescent.

Ethnic: Findings showed that 70 percent (140 respondents) were Malay followed by Indian Muslim (14.5 percent or 29 respondents), Chinese ( 4.5 percent or 9 respondents) and other ethnic group (11.0 percent or 22 respondents).

Marital Status: Majority of the respondents (96.5 percent or 192 respondents) indicated that they were never been married. Only 3.0 percent ( 6 respondents) reported that they were 'currently married' while only one respondent $(1.0 \%)$ reported to be separated.

Level of Education: The percent distribution of respondents by the high level of education were vary. Approximately 35.0 percent (70 respondents) said that they had gained certificate for SRP, 26.5 percent (53 respondents) had gained certificate for SPM, had attended secondary schools but not completed (27 percent or 54 respondents), no education (4.5 percent or 9 people), had gained diploma or degree (2 percent), completed technical certificate ( 1 percent or 2 respondents) and others ( 4 percent or 8 respondents). Overall, majority of respondents in the study had low education level. Higher level of education improves individual life in many ways particularly employability and income rate. Education also is a basis for individual growth and development. As such, poor quality schooling and lack of education increase adolescents vulnerability to social problems and exploitation.

Occupational Status: A total number of 67 respondents (33.5\%) in the study reported to work part time, 41 respondents (20.5\%) reported to had permanent job and 32 respondents $(16.0 \%)$ admitted to be unemployed. Of these total, 60 respondents $(30 \%)$ reported that they 'still study'. (see Table 2).

Table 2. Demographic profile of respondents

\begin{tabular}{ccc}
\hline Respondent Demographic Profile & (n=200) & Percentage \\
\hline Age (years) & & \\
$15-18$ & 81 & 40.5 \\
$19-21$ & 119 & 59.5 \\
Ethnic & & \\
Malay & 140 & 70.0 \\
Chinese & 9 & 4.5 \\
India & 29 & 14.5 \\
Other & 22 & 11.0 \\
Marital Status & & \\
Single & 192 & 96.0 \\
Married & 6 & 3.0 \\
Widower & 2 & 1.0
\end{tabular}




\section{Level of Education}

$\begin{array}{ccc}\text { SRP } & 70 & 35.0 \\ \text { SPM } & 53 & 26.5 \\ \text { Primary Schools } & 54 & 27.0 \\ \text { No Schooling } & 9 & 4.5 \\ \text { Diploma } & 3 & 1.5 \\ \text { Degree } & 1 & .5 \\ \text { Technical Certificate } & 2 & 1.0 \\ \text { Others } & 8 & 4.0 \\ \text { Occupational status } & & \\ \text { Student } & 60 & 30.0 \\ \text { Unemployed } & 32 & 16.0 \\ \text { Permanent job } & 41 & 20.5 \\ \text { Part Time Job } & 67 & 33.5\end{array}$

\section{Experience of Drug Use among Male Adolescents}

\subsection{The Age of Onset of Drug Use}

Figure 3 shows the age of onset of drug use of the respondents in the study. The earliest age onset of drug use reported was 8 years old. Majority of the respondents started using drugs at the age between $14-16$ (49\% or 98 adolescents). Thirty percent respondents (62 adolescents) reported to start using drug at the age between 17-19 followed by the age between $11-13$ (16\% or 32 adolescents), and the age between $8-10$ (4\% or 8 adolescents). The findings showed that the key risk periods for drug abuse are during major transition in children's lives. It is at this stage (adolescent) that children are likely to encounter drugs for the first time. Also, the involvement of adolescents in drugs at early stage of their developmental stage will affect the health and intellectual growth of adolescents. According to Foster (2012) adolescents who start abusing alcohol or drugs at an early stage of age are at much greater risk of developing an addiction later in life compared to those who misuse drugs later. (see Figure 1)

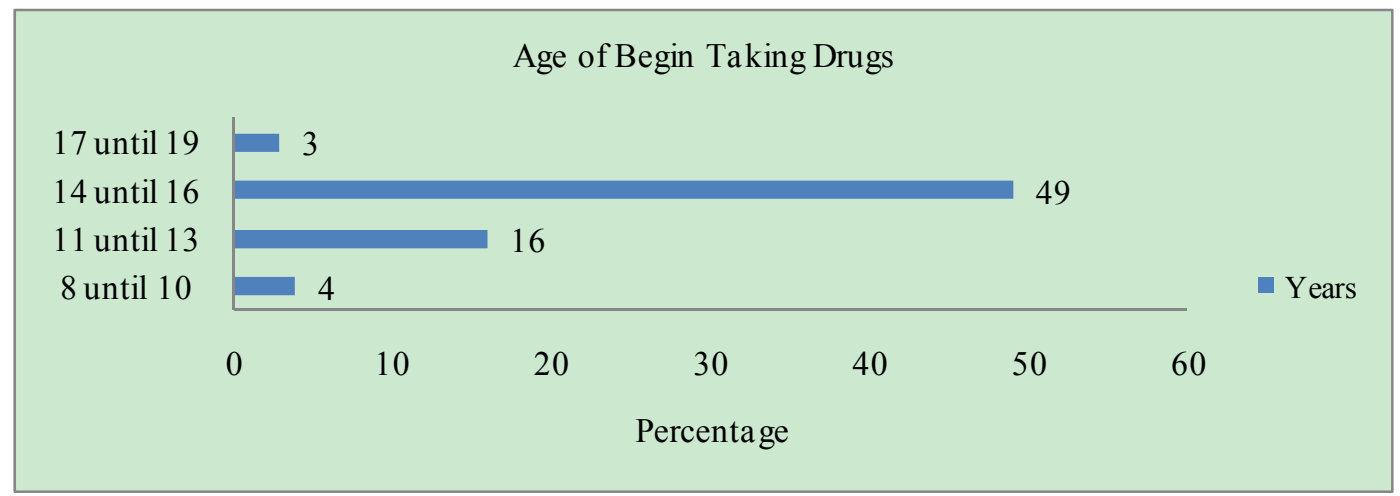

Figure 1. Age of begin taking drugs

\subsection{The Period of Drug Addiction}

The data gathered from the study showed that the mean score for drug addiction among adolescents was 3 years with a standard deviation of 2.13. Eighty respondents (40\%) admitted to experience drug addiction for 1-2 years. Meanwhile, 63 respondents (31.5\%) revealed to addict to drug for 3-4 years, followed by 5-6 years (40 respondents or $20 \%$ ), within $7-8$ years (15 respondents or $7.5 \%$ ), and remaining two respondents (or $1 \%$ ) experienced drug addiction for 11-12 years. Long time involvement with drugs has negative implications on the treatment process/outcomes. This is because the longer an individual's drug addiction is, the higher their chances of exposed to the problem of relapse. (see Figure 2) 


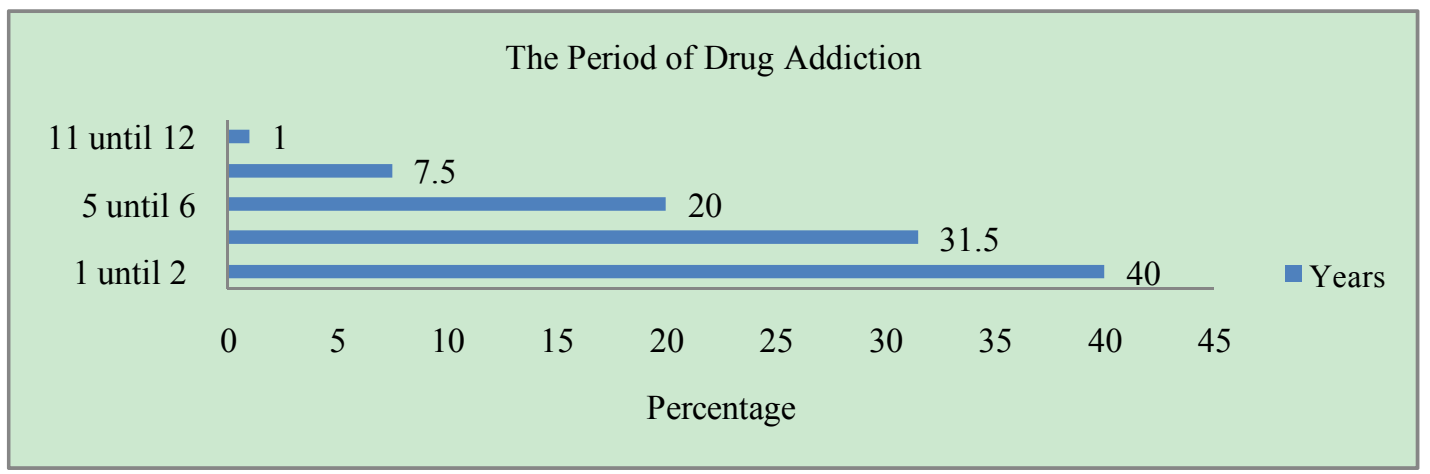

Figure 2. The period of drug addiction percentage

\subsection{Frequency of Access to Drug Rehabilitation Center}

Of total respondents, more than a half $(58.5 \%$ or 117 respondents) reported that they never been in treatment (first treatment). Sixty three respondents (31.5\%) said that to receive treatment for the second time while nine (9) respondent $(4.5 \%)$ percent said that to receive drug treatment for the third times. In summary, the minimum frequency of respondents seeking treatment in a drug rehabilitation center is one (first time) and the maximum was three. (see Figure 3)

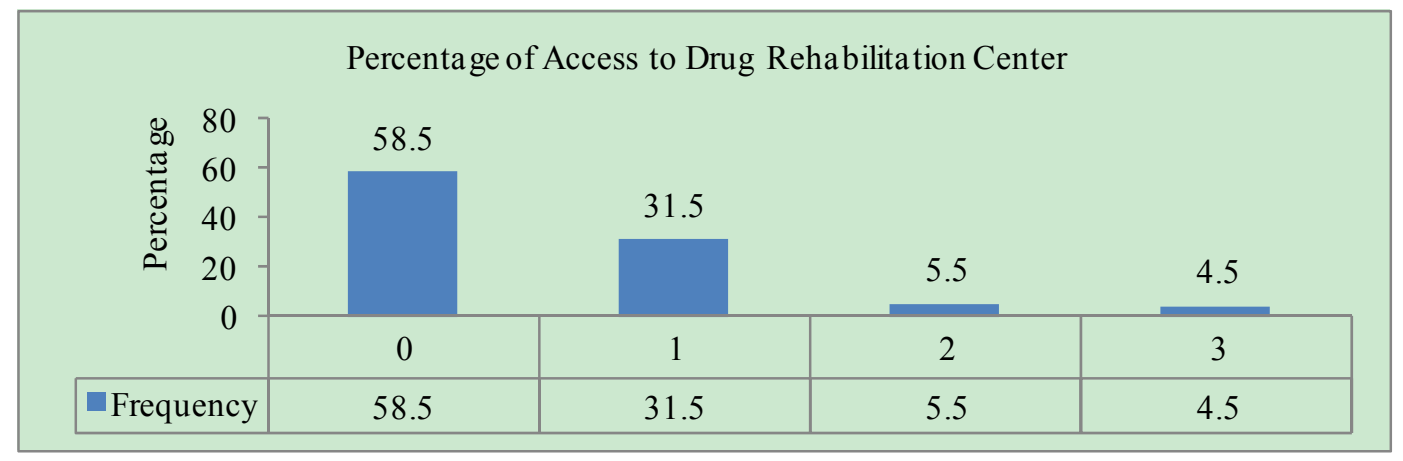

Figure 3. Percentage of access to drug rehabilitation center

\subsection{Frequency of Taking Drugs Within a Week}

Review of the frequency aspect of drugs within a week, information gathered from the study found that a total number of $93(46.5 \%)$ adolescents reported to take drugs every day while 24 respondents $(12.0 \%)$ admitted to take drugs more than two times in a day. The remaining respondents (34 or $17 \%$ ) reported that they used drugs every alternate day. This shows that the majority of respondents in the study are those with high dependency on drugs before entering a rehabilitation center for drug treatment. From the data gathered, it can be concluded that drugs use among the respondents was high. (see Figure 4).

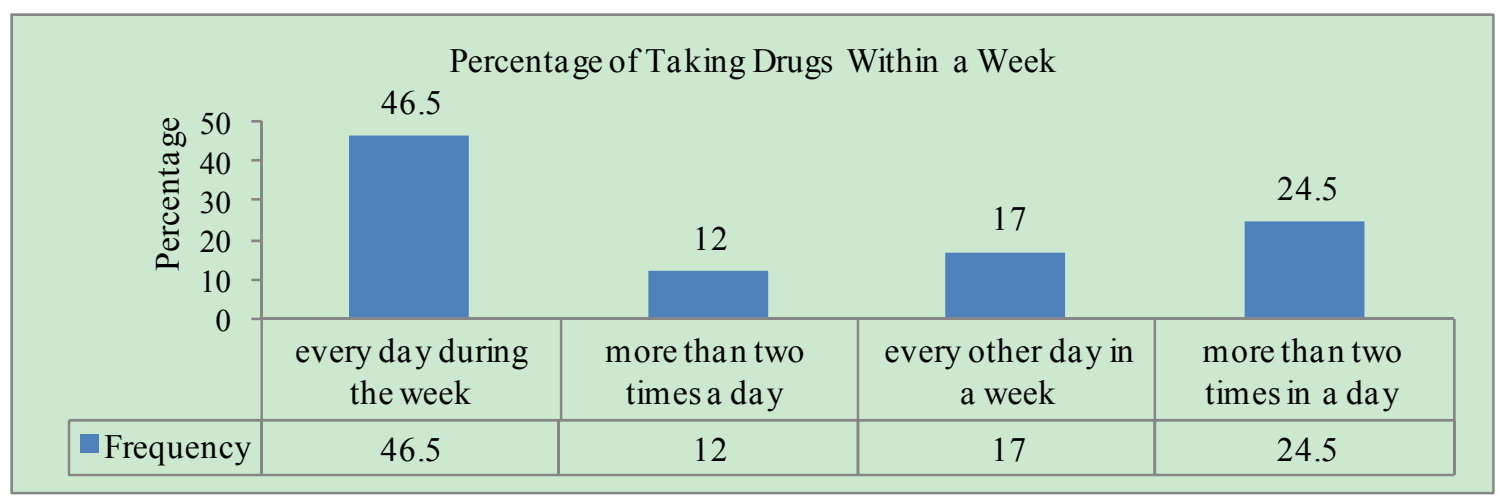

Figure 4. Percentage of taking drugs within a week 


\subsection{Resources of Drug Supply}

Adolescents often obtain illicit drugs from various sources. Our findings showed that a total number of 99 persons (49.5\%) admitted that they obtained supplies of drugs from a supplier, followed by friends (83 respondents or $41.5 \%)$, from retailer (pusher), and small portion of respondents ( $4.5 \%$ or 9 adolescents) reported to obtain drugs from other drug supply sources. The data gives the impression that the respondents obtained their drugs from various channels and easily from readily sources known or familiar to them. This greater drug availability making it hard for adolescents to stop their drug use habits and also for government to control drug access effectively. (see Figure 5)

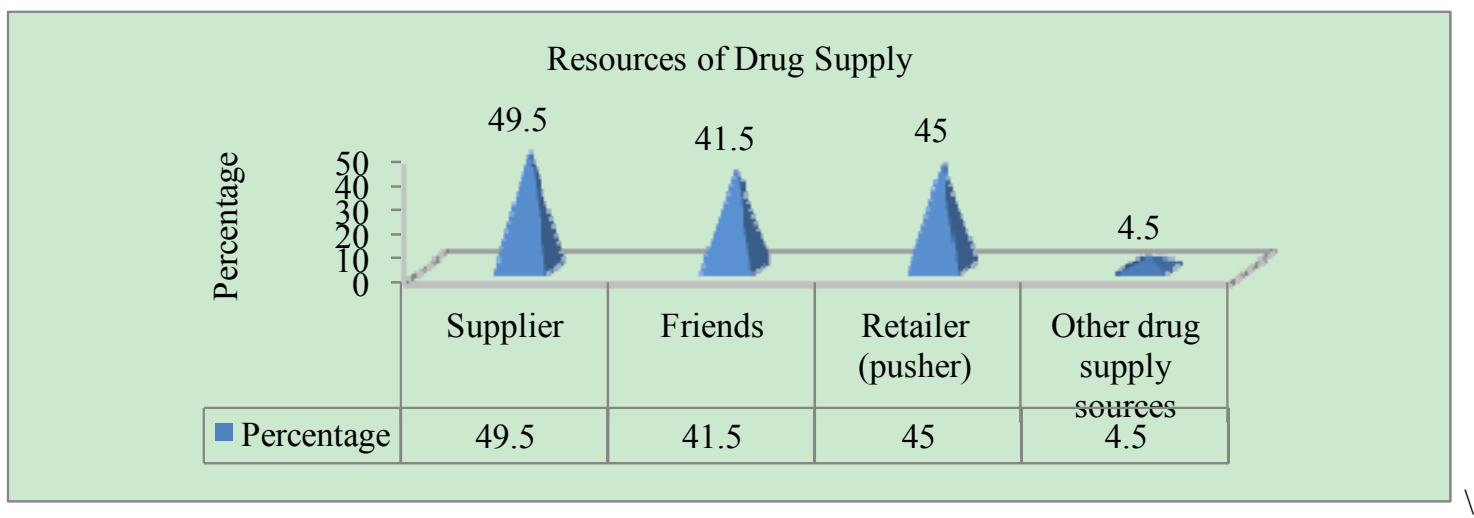

Figure 5. Resources of drug supply percentage

\subsection{Types of Drugs Used}

In general, it is expected that adolescents who involved with drugs are those who have fallen into the realm of serious drug and has taken a more dangerous drugs. This situation is confirmed by the information obtained from the respondents. Of several type of drugs inquired about in the survey, cocaine became the widely used type of drugs with 130 respondent (65\%) reported to use cocaine compared to other drugs. According to Gordon (2000), cocaine produces many negative effects on the body, including appetite suppression and increased temperature, heart rate and blood pressure. Long term of cocaine can produce paranoia and negative physical effects such as weight loss. An overdose of cocaine can raise death rate, especially if used in combination with alcohol. This study also showed 109 persons or $54.5 \%$ had used cannabis, heroin 55 people $(27.5 \%)$, amphetamine 26 people (13\%), morphine, 23 people $(11.5 \%)$ and opium 12 people $(6 \%)$. Other drugs such as gum and cough medicines were also been mentioned by 22 respondents (11\%). (see Figure 6 )

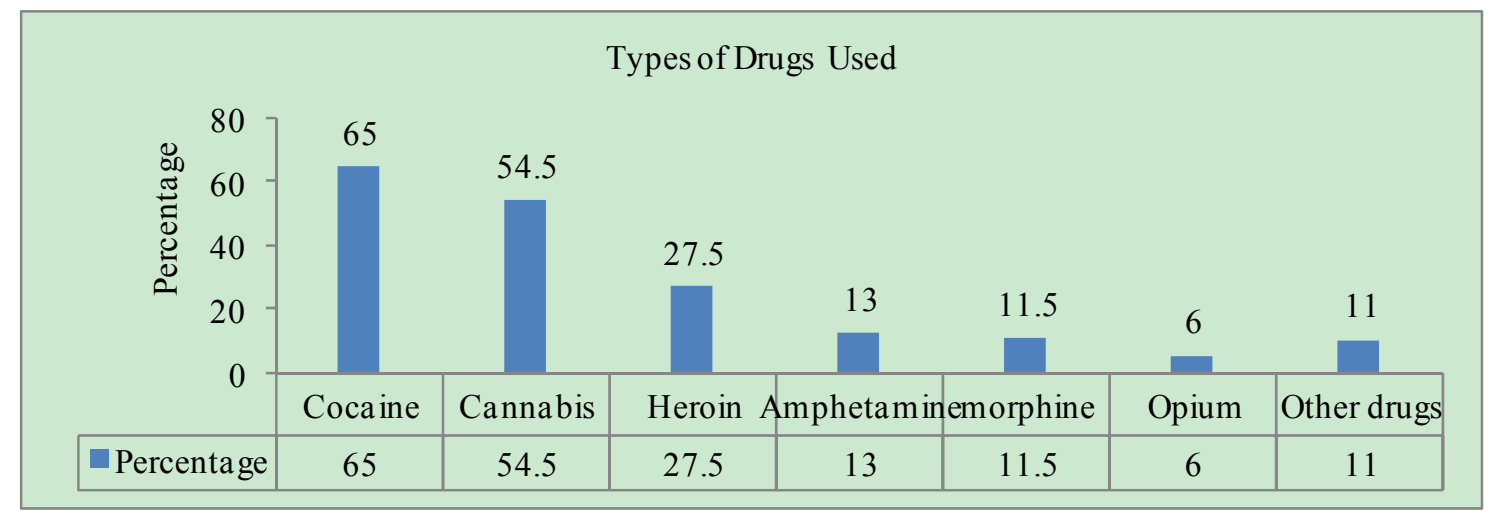

Figure 6. Types of drugs used percentage

\section{Conclusion}

Drug prevention that involves adolescents can be a powerful strategy in tackling drug problem. Energy and enthusiasim of young generations should be mobilized for a good reason. Therefore, the best methods for designing intervention and drug treatment should be made carefully by taking into consideration the profile and experience of drug used among an adolescents. It is important to equip adolescents with a broad range of skills that can help them resist the influence of drugs in variety of settings. Also, research suggests that some of the 
most effective drug abuse prevention programs take a comprehensive approach that include family, community and media intervention. Using social media website is the most common activity among adolescents nowadays. This can be used to establish prevention efforts among adolescents as a whole.

\section{Acknowledgements}

The researchers have been supported generously by Prisons Department of Malaysia and the Faculty of Social Sciences and Humanities, Universiti Kebangsaan Malaysia on UKM-GGPM-CMNB-007-2010 grant. The researchers would like to express their sincere appreciation for all the support provided.

\section{References}

Balogun, S. K. (2006). Chronic intake of separate and combined alcohol and nicotine on body maintenance among albino rats. Journal of Human Ecology, 19(1), 21-24.

Boles M., \& Miotto K. (2003). Substance use and violence: A review of the literature. Aggression and Violent Behavior, 8(1), 55-174.

Boyd, C. J., McCabe, S. E., Cranford, J. A., \& Young, A. (2006). Adolescents' motivations to abuse prescription medications. Pediatrics, 118(6), 2472-2480. http://dx.doi.org/10.1542/peds.2006-1644

Center for Substance Abuse Treatment. (1999). Treatment of Adolescents with Substance Abuse Problems. Treatment Improvement Protocol (TIP) Series, No. 32. DHHS Publication No. (SMA) 99-3283. Rockville, MD: Substance Abuse and Mental Health Services Administration.

Chermack, S., \& Blow, F. (2002). Violence among individuals in substance abuse treatment: The role of alcohol and cocaine consumption. Drug and Alcohol Dependence, 66(1), 29-37. http://dx.doi.org/10.1016/S0376-8716(01)00180-6

Crowe, A. H. (1998). Drug Identification and Testing in the Juvenile Justice System: Summary. Washington, DC: Office of Juvenile Justice and Delinquency Prevention, Office of Justice Programs, U.S. Department of Justice.

Davis, W. M. (1996). Psychopharmacologic violence associated with cocaine abuse: Kindling of a limbic dyscontrol syndrome? Progress in Neuro-Psychopharmacology and Biological Psychiatry, 20(8), 1273-1300. http://dx.doi.org/10.1016/S0278-5846(96)00126-1

Dennis, M. L. (2002). Treatment Research on Adolescents Drug and Alcohol Abuse: Despite Progress, Many Challenges Remain (Invited Commentary). Connection. Washington, DC: Academy for Health Services Research and Health Policy.

Fauziah Ibrahim, \& Naresh Kumar. (2009). Factors Effecting Drug Relapse in Malaysia: An Empirical Evidence. Asian Journal of Social Science, 5(12), 37-44.

Fauziah Ibrahim, Arifin Zainal, Wan Shahrazad Wan Sulaiman, Lukman Mohamad, Roseliza Murni, \& Zainah Ahmad Zamani. (2010). Measuring Motivational Readiness for Change among Drug Addicts in Malaysia: A Descriptive Analysis. The Social Science Journal, 5(5), 429-432.

Fauziah, I, Khadijah, A., Noremy, M. A., Sarnon, N., Lukman, Z. M., Mohamad, S. M., Subhi, N., ... Suzana, M. H. (2012). The Role of Family towards Current Adolescence Challenges: Drug Prevention and Living Without Drugs. The Social Sciences, 7(2), 341-345.

Fisher, D. G, Reynolds, G. L, Ware M. R., \& Napper, L. E. (2006). Recreational Viagra use and sexual risk among drug abusing men. Am J Infect, 2(2), 107-114. http://dx.doi.org/10.3844/ajidsp.2006.107.114

Foster, L. (2009). Teen Alcoholism and Drug Addiction. Retrieved from http://www.everydayhealth.com/addiction/addiction-in-adolescence.aspx

Friedman, R. A. (2006). The changing face of teenage drug abuse - the trend toward prescription drugs. New England Journal of Medicine, 354(14), 1448-1450. http://dx.doi.org/10.1056/NEJMp068010

Giedd, J. (2008). Interview. Retrieved May 20, 2012, from http://www.pbs.org/wgbh/pages/frontline/shows/teenbrain/interviews/giedd.html

Gogtay et al. (2004). Dynamic mapping of human cortical development during childhood through early adulthood. Proceedings of the National Academy of Sciences of the United States of America, 101(21), 8174-8179. http://dx.doi.org/10.1073/pnas.0402680101 
Gordon, S. M. (2000). Adolescents Drug Use: Trends in Abuse, Treatment and Prevention. Caron Foundation, Wernersville, PA.

Kokotailo, P. (1995). Physical health problems associated with adolescent substance abuse. In E. Rahdert, \& D. Czechowicz (Eds.), Adolescent drug abuse: Clinical assessment and therapeutic intervention (pp. 112-129). Bethesda, MD: National Institute on Drug Abuse.

Lejuez, C. W., Bornovalova, M. A., Daughters S. B., Marina, A., \& Curtin, J. J. (2005). Differences in impulsivity and sexual risk behavior among inner-city crack/cocaine users and heroin users. Drug and Alcohol Dependence, 77(2), 169-175. http://dx.doi.org/10.1016/j.drugalcdep.2004.08.013

Leshner, A. I. (2005). Oops: How casual drug use leads to addiction. Retrieved May 20, 2012, from http://www.drugabuse.gov/Published_Articles/Oops.html

MacDonald, S., Erickson, P., Wells, S., Hathaway, A., \& Pakula, B. (2008). Predicting violence among cocaine, cannabis and alcohol treatment clients. Addictive Behaviors, 33(1), 201-205. http://dx.doi.org/10.1016/j.addbeh.2007.07.002

Moore, T. M., \& Stuart, G. L. (2003). A review of the literature on marijuana and interpersonal violence. Aggression and Violent Behavior, 10(2), 171-192. http://dx.doi.org/10.1016/j.avb.2003.10.002

National Anti-Drug Agency of Malaysia. (2010). Drug Report. Putrajaya: Kuala Lumpur

Nnachi, R. O. (2007). Advanced psychology of learning and scientific enquiries. Enugu: J.J. Classic Publishers Ltd.

Okoye, N. N. (2001). The adolescents and hard drugs: A psychological concern in R.U.N. In Okonkwo, \& R. O. Okoye (Eds.), The Nigerian adolescent in perspective. A Publication of the Nigerian Society for Education.

Stuart G. L., Temple J. R., Follansbee K.W., Bucossi. M. M., Hellmuth, J. C., \& Moore, T. M. (2008). The role of drug use in a conceptual model of intimate partner violence in men and women arrested for domestic violence. Psychology of Addictive Behaviors, 22(1), 12-24. http://dx.doi.org/10.1037/0893-164X.22.1.12

Synder, H. N., Sickmund, M. (1999). Juvenile Offenders and Victims: National Report. Washington, DC: National Center for Juvenile Justice.

United Nations Organizations on Drug Council (UNODC). (2005). World Health Organization Expert Committee on Dependence Producing Drugs. Fourteenth Report Urban Adolescents. Child Development, 61, 2032-2046.

Wells, R. S., Fisher, D. G., Fenaughty, A. M., Cagle, H. H., \& Jaffe, A. (2006). Hepatitis A Prevalence among Injection Drug User. Clinical Laboratory Science, 16(1), 12-17. 